\title{
LUT
}

Lappeenranta

University of Technology

\section{Product Processes based on Digital Twin}

Alaei Nima, Rouvinen Asko, Mikkola Aki, Nikkilä Raimo

This is a Author's accepted manuscript (AAM) version of a publication published by Springer Vieweg, Wiesbaden

in 5th International Commercial Vehicle Technology Symposium Kaiserslautern

DOI: 10.1007/978-3-658-21300-8_15

Copyright of the original publication: (c) Springer Fachmedien Wiesbaden GmbH 2018

Please cite the publication as follows:

Alaei, N., Rouvinen, A., Mikkola, A., Nikkilä, R. (2018). Product Processes based on Digital Twin. 5th International Commercial Vehicle Technology Symposium. p. 187-194. DOI:

10.1007/978-3-658-21300-8_15 


\title{
Product Processes based on Real-Time Simulation
}

\author{
Nima Alaei ${ }^{1}$, Asko Rouvinen ${ }^{2}$, Aki Mikkola ${ }^{1}$ and Raimo Nikkilä ${ }^{2}$ \\ ${ }^{1}$ Lappeenranta University of Technology, Skinnarilankatu 34, 53850 Lappeenranta, Finland \\ ${ }^{2}$ Mevea Ltd., Laserkatu 6, 53850 Lappeenranta, Finland \\ nima.alaeillut.fi
}

\begin{abstract}
Product development is performed by proficient designers, who make their best effort to understand customer needs and desires via verbal or written interview. This approach becomes cumbersome if a product design undergoes revolutionary changes. In this paper, potential of real-time simulation models based on Multibody System Dynamics are utilized as a tool to interpret customers' needs. The complete real-time simulation model can be considered as interaction of several subsystems which are environment, work process, mechanics, actuators, control system and user input. A mechanical subsystem based on the use of multibody system dynamics includes modeling of mechanical bodies, force elements acting between bodies, joints connecting bodies, and contacts. In this way, three main area of applications are introduced consistently. Firstly, benefits of the process is discussed in Research and Development and Product Development domain. Latter comes R\&D service business part and eventually authors investigate effect of the approach in marketing and sales.
\end{abstract}

Keywords: Real-time Simulation, Product Development, Multibody System Dynamics.

\section{Introduction}

In recent years, simulation-based product development has received a notable attention in scientific publication [1]. Same trend is observable with deployment and popularity of digital twin, which is designed to respond need of cheaper and repeatable product investigation. This is happening thanks to recent major innovation and improvement in IT technologies, which have enabled digital tools to be applied for multi-dimensional aspect of the simulation work. Following the recent advances, this paper is discussing the newly emerged approach, as a substantial potent platform for product processes.

Traditionally, product and service development decisions have been made by expert staff far from end-users. Their decisions have been based, for the most part, on relevant technical aspects. In the product development work, digital analysis tools such like finite element method, multibody system dynamics are used to speed up design process and to ensure that a product will have targeted technical features. In the product process, customer needs and desires are solicited via verbal or written interview. For a completely new product or for major product changes, this approach is challenging as it is difficult to describe a concept-level product to customers. It is equally difficult for the customers to fully understand the advantages or disadvantages of the upcoming product. Furthermore, if the product contains a radical innovation, customers may not even be able to articulate what their specific needs related to the product would be like [2]. Accordingly, the major drawback associated to the current process is that the usability issues and fulfilment of customer needs can be addressed only at the late phases of the R\&D process, often after first physical prototype is build. This is expensive, time-consuming and often does not fully serve customer needs. This can be considered as severe drawback as the main focus of these process improvements is moving away from the purely technical aspects and moving towards enhancing the user experience.

User/customer demands must be better addressed in future products and services. This problem can be solved by developing real-time simulation based approach for product processes. This vision can be accomplished, in practice, by developing a toolset that will allow the multiple stakeholders to access product research and development through virtual worksites providing fully configurable, real-time, physics based virtual prototyping. According to the vision, digital tools are no longer a tool set of product development team but used as a bridge between product development and the customers. This allows product development team to introduce new concepts to customers in early phase of $\mathrm{R} \& \mathrm{D}$ process, much before first physical prototype is build. Customers, in turn, can modify models according to their needs and this way express requirements in a clear technical manner. In practice, required toolset can be obtained by employing multi-physical real-time multibody system approach.

This paper describes possible uses for real-time simulation based product processes. The primary objective is to explain how real-time simulation tools would increasingly represent real-world functionality. 


\section{Real-Time Simulation of Multibody System Dynamics}

The complete real-time simulation model can be considered as interaction of several subsystems which are environment, work process, mechanics, actuators, control system and user input. Each subsystem interacts with other subsystems to provide complete simulation process. As an example, the main role of the user is to provide reference signal to the control system via a control console (pedal, joystick etc.), which can be translated as input signals for the control system. The actuators subsystem, in turn, is functional to compute the force which is provided to the mechanic subsystem after receiving data signal from the control system.

Description of mechanical subsystem is based on the use of multibody system dynamics and it includes modeling of mechanical bodies, force elements acting between bodies, joints connecting bodies, and contacts. The actuator subsystems producing magnitudes of force elements can have a wide variety of component types, such as tires, hydraulics, electric drives, reeling etc.

Multibody system dynamics is generally built through certain steps. In first step, comprehensive model of body physics including masses, positions of center of mass, three-dimensional definition of inertia, flexibility characteristic are defined to from a basis for Multi-body model of the system. Initial Kinematics of the bodies then are implemented in global system of coordination, so in the start of simulation, position and orientation is assumed to be known. This makes the formation of body reference frames with respect to global coordinates. Next step is definition of the constraints, where the joints that connect the different bodies in the model are described. In this way, each body behave according to the limits that are imposed by the other connected bodies. This restriction are conventionally categorized geometrically as translational or rotational, depending on nature of the restriction imposed by the joint. Then forces which are acting on the bodies and constraints are mathematically implemented into the system. [3]

Mobile machineries are traditionally empowered by hydraulic actuators, such as hydraulic cylinders and motors. Hydraulic cylinders are used to get translational movement from a pressure source, main parameters in this case are cylinder piston diameter, stroke length, end-damping coefficient, end-spring stiffness and leakage properties. The main modelling approach which is widespread in simulation softwares is semi-practical method that couples data based on real experiments and scalable measurements to the theoretical approaches. Fig. 1 have shown the main elements, involved in multibody modelling of a mobile machine. [3]

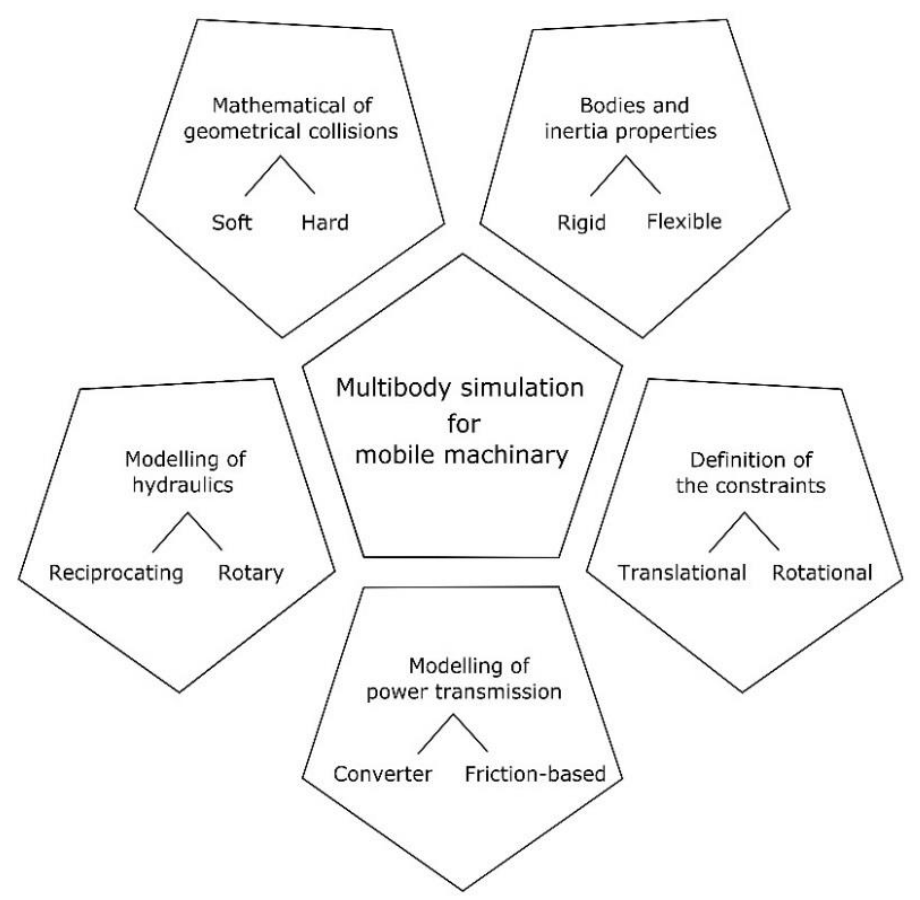


Fig. 1. Main multibody simulation concepts involved in a virtual mobile machine model

In Fig. 1, the power transmission is divided into converter and friction-based component groups. Converters will include spur gears, rack and pinions, planetary gears and other gearboxes, while brakes and clutches are incorporated with friction-based forces. Wherein the main parameters are relative velocity, contact normal load, contact tangential load, friction coefficient and Stirbeck curve properties.

\section{Uses of simulator-driven processes}

\subsection{Research and Development and Product Development}

Product development is among the essential processes for companies as it can influence the competitive success, adaptation and renewal of organizations [4]. The vast literature focusing on product development has found a plethora of reasons behind a new product success (as well as behind its failure), here we focus only on some. Ancona and Caldwell [5] found out that the most successful product-development teams engaged in a wide-ranging external communication strategy, combining so-called ambassador and task-coordination behaviors that helped these teams to secure resources, gain task-related information, and eventually enhance performance. Community-based simulator driven process enhances companies' possibilities to make customers an important resource for their product development efforts [6].

Connection between Digital Mock-Up and other processes in product development phases is depicted in Fig. 2. Product development in this scenario starts at concept design such as CAD drafting. In next steps, progress of the different phases is bonded with a functional Digital Mock-Up so units like hardware and software in loop can communicate with CAD tools through the Digital Mock-Up intermediary. Each step of iteration through Digital Mock-Up help designers to avoid unseen discrepancies and coordinates work of different engineering disciplines [7].

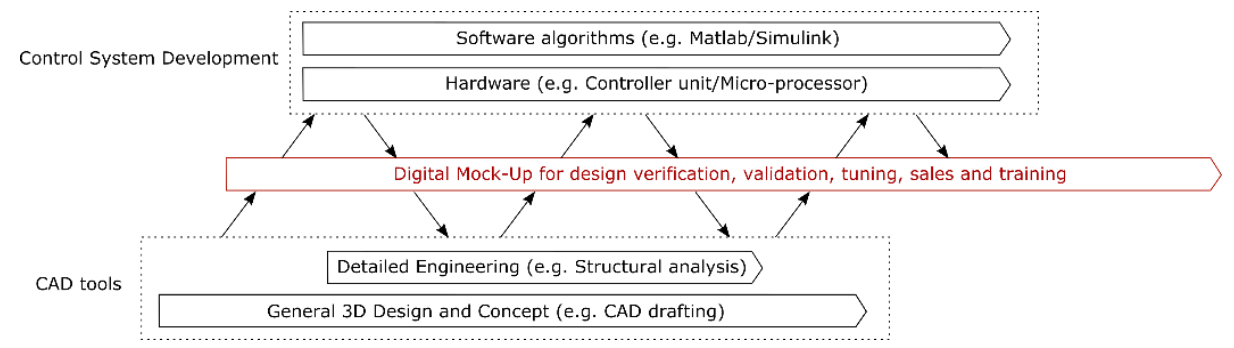

Fig. 2. Simulator-driven process in product development

An example of the use of the "virtual machine" in the product development could be the planning of the new mobile machine. With a simulator-driven approach a company can recruit a large number of test -drivers for several (virtual) prototypes and beta versions. In this approach, the classic idea of testing various versions of the products is combined with customer-driven innovation. Well-planned and implemented simulation-based test cycle means that in the virtual environment test users could operate in different conditions and with different features in a shorter time period than in real-world conditions. Furthermore, a company could also add game-like elements into the testing platform. This gamification [8] can increase the commitment of the test users and may provide user experiences from even a larger number of potential users.

The benefits for product and development included e.g. better concept design as an outcome, as well as savings in materials in final design as the construction can be optimized based on user data. A basis for this is that user data can be gained from larger pool of users than with the use of classic marketing research methods.

Several case examples, including a pantograph/catenary suspension system that is modelled via ADAMS software as well as a systematic approach for modelling mechatronic parts for car manufacturing, which are in concern of 
this group of multibody modelling application are presented in [9]. In addition to previously mentioned applications, one typical example for usage of simulation driven product development is schematically shown in Fig. 3. In such applications when the controller hardware and software are identical to the actual machine, results and diagnosis is performed by help of simulated model. Thus, risk of actuator damage is reduced, wherein time is saved within data collection process.

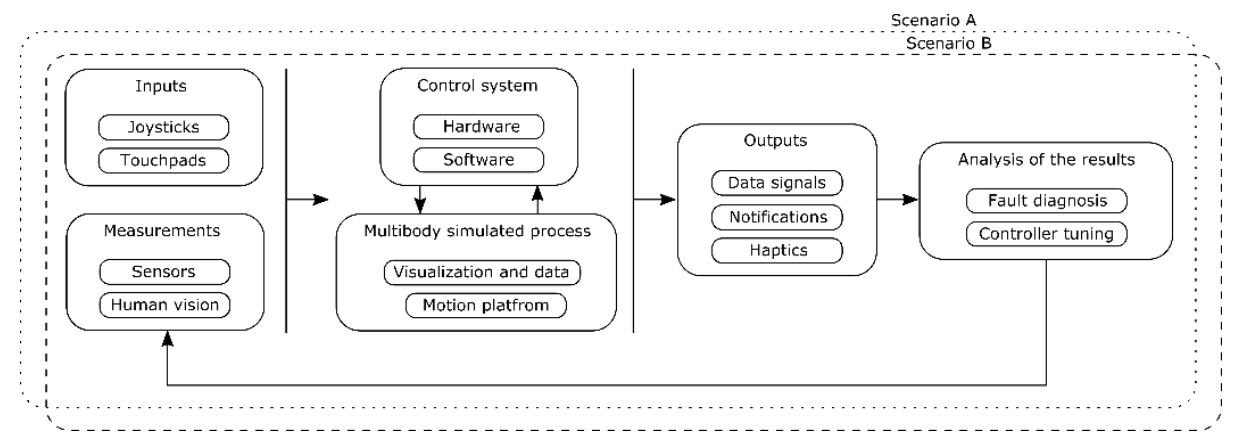

Fig. 3. Application of the simulation based product development in controller tuning scenarios

\subsection{R\&D service business}

Fig. 4 schematically explains role of a functional Digital mock up as main part of virtual R\&D as sample process is under progress [10]. In this scenario, there are three main objectives for a Digital Mock-Up. It will ensure the product specification meets the requirements which are defined in initial phases. Moreover, it makes an appropriate demonstration for stakeholders earlier than first prototyping phase, therefore they can understand and involve the development process. The last benefit of these virtual R\&D toolsets is wide availability and repeatability of virtually experienced data in last chains of R\&D process, namely production, sales and training. Such virtually collected data make a large asset out of possible various trials, whilst operation is handled safely.

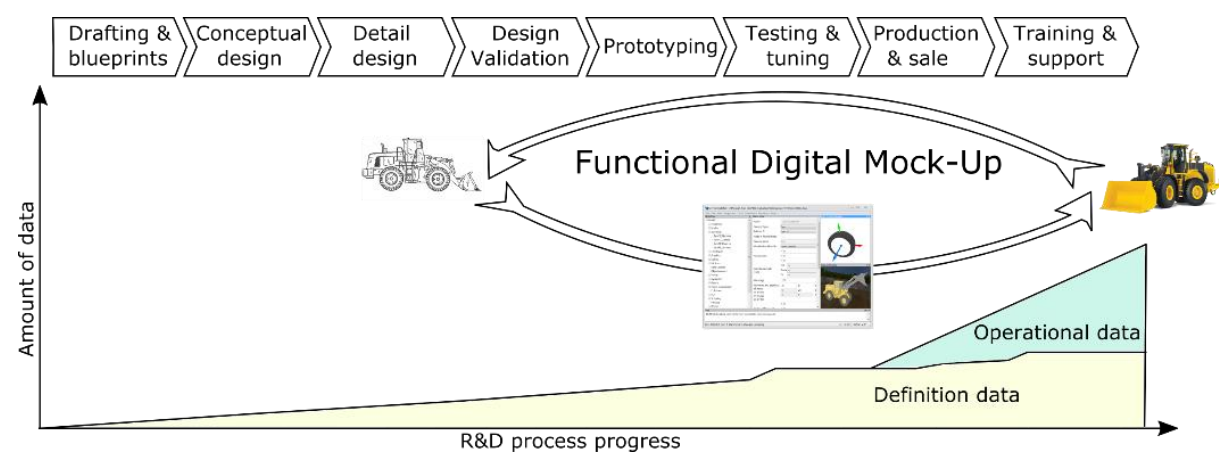

Fig. 4. Schematic role of a functional Digital Mock-Up during R\&D process

Normet is considered as a case study for above mentioned area of application. The company is active in mining machineries section and relevant services. Underground construction, processing and logistics indicates the company's main field of the interest. Through simulation tools which are founded based on Multibody simulation, Normet were able to reach average of 23 percent higher efficiency of concrete spraying. [11] Moreover, the concrete distribution on inner wall of tunnels can be monitored and subsequently further improvement is possible through analysis of the results. Fig. 5 demonstrates a screenshot of real-time simulation related to the mentioned process. 


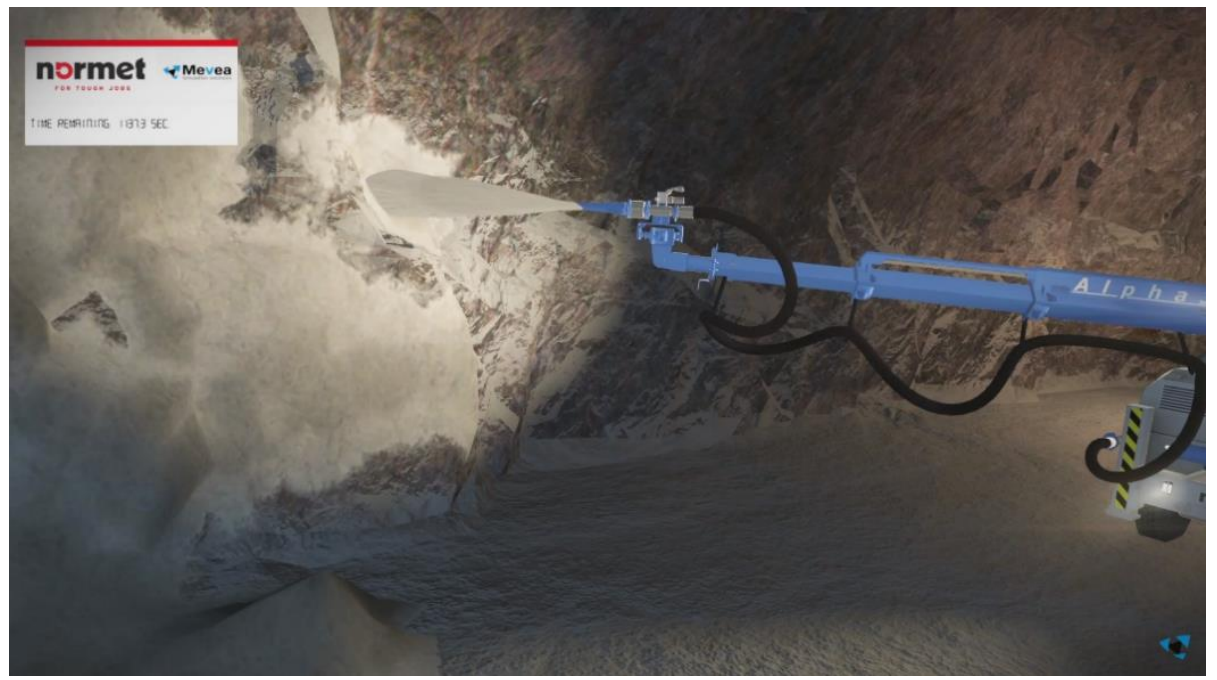

Fig. 5. Application of multibody dynamic simulation for operator training [11]

\subsection{Marketing and sales}

Schneider and Hall [12] suggest that the 'biggest problem' in new product launch is 'lack of preparation'. With this they mean that often companies are so focused on designing and manufacturing new products that they postpone the hard work of getting ready to market them until it is too late (ibid). By introducing community-based, real-time tools that simulate real-world functionality for potential customers, a more realistic idea of different value-drivers can be gained. A simulation can substitute real life observation with voluminous realistic data. More information on how potential users cope in different usage situations can help marketers and sales people to customize the products for customers.

A new practical example of using the simulator in marketing and sales can be found in products with different additional value-creating features. A car dealer may have a simulator in a show room and potential customers can test the effect of various additional features (more effective engine, etc.) on their driving experience with less hassle.

\section{Discussion and Conclusions}

Since advanced multibody simulations technologies make it possible to describe increasingly complex mechanical systems, the possible benefits and uses of these technologies need be considered. This paper has presented three interesting areas of application for real-time, simulator-driven processes.

This approach increase competence of the mobile machinery manufacturer, in the way to establish a systematic approach of adapting fast changes. A wide diversity of tasks can be conducted through the simulation platform in the three presented areas, built on basis of Multibody dynamics modelling. For near future development, the platform intention is not only to improve user experience and feedback in features of simulation tools, but also compatibility of the system for assembling and integrating e-learning, virtual reality, internet of the things and crowd sourcing is passing through such platforms. 


\section{References}

1. Jahangirian, M., Eldabi, T., Naseer, A., Stergioulas, L. K., \& Young, T. Simulation in manufacturing and business: A review. European Journal of Operational Research, 203(1), 1-13 (2010).

2. Mohr J., Sengupta S., Slater S.: Marketing of high-technology products and innovations. 3rd edn. Prentice Hall, Upper Saddle River, NJ (2010).

3. Baharudin M.E., Rouvinen A, Korkealaakso P., Mikkola A.: Real-time multibody application for tree harvester truck simulator. Proceedings of the Institution of Mechanical Engineers, Part K. In Journal of Multi-body Dynamics 2014, vol. 228(2), pp. 182-98. SAGE, California (2014).

4. Brown S.L., Eisenhardt K.M.: Product development: Past research, present findings, and future directions. Academy of management review 20(2), 343-378 (1995).

5. Ancona D. G., Caldwell D.F.: Bridging the boundary: External process and performance in organizational teams. Administrative Science Quarterly 37, 634-665 (1992).

6. Hippel E. von.: Get New Products from Customers. Harvard Business Review 60(2) 117-22. (1982)

7. Song In-Ho and Chung Sung-Chong.: Synthesis of the digital mock-up system for heterogeneous CAD assembly. Computers in Industry 60(5), 285-295 (2009).

8. Hamari J., Koivisto J. J., Sarsa H.: Does gamification work? a literature review of empirical studies on gamification, System Sciences (HICSS) 47th Hawaii International Conference 2014, pp. 3025-3034 IEEE (2014).

9. Larsson, T. Multibody dynamic simulation in product development. Doctoral dissertation Luleå tekniska universitet, (2001).

10. Garbade R., Dolezal W. R.: Evolution of the Digital Mock-up (DMU) at Airbus to the Centre of Aircraft Development. Future of Product Development 2007, 3-12 (2007).

11. Mevea simulation Homepage, http://www.mining-technology.com/contractors/roofing/normet, last accessed 2017/11/21.

12. Schneider J.,Hall, J. Why most product launches fail. Harvard Business Review (April), 21-23 (2011). 